\title{
ENCOURAGING INNOVATION: TEN RESEARCH PRIORITIES FOR ACHIEVING UNIVERSAL ACCESS TO HIV/AIDS PREVENTION, TREATMENT AND CARE IN EUROPE BY 2010
}

\author{
Jeffrey V. Lazarus ${ }^{1,2}$, Ulrich Laukamm-Josten ${ }^{1}$, Rifat A. Atun ${ }^{3}$, Jerker Liljestrand ${ }^{2}$, Ida Vase ${ }^{1}$, Srdan Matic ${ }^{1}$ \\ ${ }^{1}$ Communicable Diseases Unit, WHO Regional Of ce for Europe, Copenhagen, Denmark \\ ${ }^{2}$ Faculty of Medicine, Lund University, Sweden \\ ${ }^{3}$ Centre for Health Management, Tanaka Business School, Imperial College, United Kingdom
}

\begin{abstract}
SUMMARY
When the HIV epidemic officially hit western Europe in the early 1980s, central and eastern Europe were almost completely spared due to the isolation of the Soviet Union. However, in the mid-1990s, reported new cases of HIV in eastern European countries began to increase exponentially. While there have been many declarations and strategies addressing HIVIAIDS, today the goal is universal access to HIVIAIDS prevention, treatment, care and support services by 2010. The articles included in this thematic issue of the Central European Journal of Public Health on HIVIAIDS reflect this, while the ten priorities listed below are immediate and sometimes innovative research needs in the context of preventing HIV among the most-at-risk populations. While by no means exhaustive, they are intended to point out gaps in existing knowledge and thus serve as inspiration for future research efforts.
\end{abstract}

Key words: coinfections, health policy, HIVIAIDS, research, Europe

Address for correspondence: J. V. Lazarus, WHO Regional Of ce for Europe, Scher gsvej 8, DK-2100 Copenhagen O, Denmark. E-mail: jla@euro.who.int

\section{INTRODUCTION}

When the HIV epidemic hit western Europe in the early 1980s, central and eastern Europe were almost completely spared due to the self-imposed isolation of the Soviet Union and its allies. The stabilisation of the epidemic in western Europe in the early 1990s, with relatively low prevalence and low but steady incidence, was the clear result of harm reduction and other prevention efforts. Today, men who have sex with men (MSM) continue to be the main risk group in western Europe, along with recent migrants from sub-Saharan African countries.

In the mid-1990s, after the break-up of the Soviet Union, reported new cases of HIV in eastern European countries began to increase exponentially. The epidemic in these countries has been primarily driven by injecting drug use and is rapidly spreading to the sexual partners of injecting drug users (IDUs) (1). In this part of the WHO European Region, which includes central Asia, prevention and treatment are woefully inadequate. In central Europe, on the other hand, the situation has remained stable, although conditions that promote HIV transmission, including sex work and drug injection, which often overlap, are present.
The articles in this special issue of the Central European Journal of Public Health on HIV/AIDS address a range of topics, from the perspectives of researchers, practitioners, advocates and other experts, many of whom are based in central and eastern Europe. The call for papers was launched as an opportunity to present new data, but also to share experiences and concerns which is reflected in the articles in this issue as the pandemic continues to escalate.

Our concern here, however, is that in past, HIV/AIDS research as a whole has prioritized biomedical solutions such as antiretroviral therapy, pre-exposure prophylaxis, microbicides and vaccines. The ten priorities for 2010 listed below reflect immediate and sometimes innovative research needs in the context of preventing HIV among the most-at-risk populations. While by no means exhaustive, they are intended to point out gaps in existing knowledge and thus serve as inspiration for future research efforts. New research, including operational research, is crucial to increasing our understanding of the epidemic and its dynamics better, and it must include behavioural studies and social and political analyses of national experiences throughout the region. 


\section{POPULATIONS WITH HIV}

\section{Increasing HIV Cases among Men who Have Sex with Men}

In the European Region, the HIV epidemic has mainly affected the male population, and the first research priority is the increasing number of reported HIV cases among MSM, particularly in western Europe. The practice of serosorting among MSM (deliberate and consensual unsafe sex among HIV-positive men) may have led to the phenomena of increasing HIV and sexually transmitted infection (STI) rates that otherwise may be misinterpreted as increased risk behaviour of MSM at large. Serosorting has appeared as a gay lifestyle feature but has never been promoted as "risk-reduction" as it is sometimes referred to (2). On the one hand, this helps explain the increase of syphilis and other STIs among MSM; on the other hand the increase of HIV transmission among MSM may be attributed to this practice. If serosorting "goes wrong" - i.e. an HIV-positive man has sex with a negative one - the transmission risk may be higher than normal because of acute HIV viraemia or coinfection with ulcerative STIs.

The new US Centers for Disease Control and Prevention (CDC) slogan "Increased testing is the most effective and least controversial way to discourage risky behaviour” may be problematic in this context. The "Serostatus Approach to Fighting the HIV Epidemic" (SAFE) (3) may have hidden side-effects if this leads to less condom use among seropositive partners and e.g. superinfection (4), whose clinical importance is still unclear or STIs, which when ulcerative can increase HIV transmission. Concordant couple research could close the gap of knowledge and lack of public health advice on this issue.

Very little is known about MSM in eastern Europe, and while the number of registered cases for this risk group remains low, it is widely believed to be substantially underreported due to homosexual activities being illegal or at least highly stigmatized in the countries there (5). More research is needed into risk behaviour and HIV prevalence in this population.

\section{HIV/AIDS in Prisons}

The second priority area is HIV prevention in prisons, particularly prevention strategies, and again the main target population is male. HIV prevalence for prisoners is $5-10$ times higher than for the general population in some countries (6). United Nations guidelines recommend that HIV prevention and care in prisons should be equivalent to that in the surrounding community (7), and yet basic harm reduction materials such as condoms and clean injecting equipment are often unavailable.

In eastern Europe there is still time to contain the epidemic, but research on HIV in prisons there is especially scanty. National experiences with harm reduction in prisons need to be examined and publicized, including the reasons for any lack of access to condoms and syringes. Prison conditions, including violence against both women and men, are some of the other relevant issues that are under-represented in HIV research.

Knowledge about the availability of HIV treatment in prisons, including highly active antiretroviral therapy (HAART), is similarly spotty and it would be useful to consider whether community health systems would be more effective than vertically organized prison health systems. Furthermore, since TB rates are also much higher in prison settings, the need to model TB and HIV coinfec- tion and drug resistance in the treatment of both is of particular relevance for incarcerated populations. Studies are needed to map where prisons have TB programmes and whether they are linked to HIV prevention and treatment programmes.

\section{Injecting Drug Use, Generalized Epidemics and HIV/AIDS}

At present, we are unable to answer the question "Would we be able to detect independent epidemics of sexual HIV transmission early in their development, in countries where transmission is driven by injecting drug use". The natural course of the current HIV epidemic, where young men get infected by injecting drugs, leads to at least an equal number of women (their partners) getting heterosexually infected. Though this is not yet a signal that the epidemic is becoming generalized, it is the epidemic's natural course. That this development is not being effectively blocked is addressed under No. 8 (below) on discordant couples.

An independent sexually transmitted epidemic would go beyond women infected by male IDUs. The first sign of such an independent transmission cycle would therefore be an increasing number of men becoming infected with HIV, who show no markers for hepatitis C (a proxy marker for injecting drug use) or hepatitis B (a proxy marker for MSM), or who claim that they are infected by a woman who does not inject drugs (they may know). This concept to actively look for early signs of such an epidemic has not been fully understood or applied. In-depth interviews with men, who have an unknown transmission route or claim to have become heterosexually infected and using proxy markers for surveillance of transmission modes have not been widely established. Moreover, the high proportion of men with an "unknown transmission" route in surveillance data in eastern Europe (8) may mask homosexual or IDU transmission rather than heterosexual transmission.

The use of HIV serological incidence assays becomes important to distinguish recent from older infections in IDUs to decide whether harm reduction interventions are actually covering a high enough proportion of IDUs to be effective.

\section{SOCIAL IMPACTS OF PREVENTION AND TREAT- MENT}

\section{Resistance to Evidence-based Interventions}

Several European countries have resisted evidence-based interventions such as harm reduction (e.g. opioid substitution therapy) and school-based sex education. These systemic failures need to be better understood. Is opposition due to a poor comprehension of, or professional opposition to, evidence-based medicine, often linked to anti-Western sentiments or perceived challenges to the existing order, or is there another agenda at work? (9). Such research should utilize both qualitative and quantitative methods, for instance by assessing the knowledge of narcologists, infectious disease specialists and health policy-makers on the principles of evidence-based medicine.

\section{Impact of Criminalisation}

Intentionally transmitting HIV or exposing another person to it has been criminalised in several countries, but it remains a highly contentious issue (10). Can a person who is unaware of his or her 
serostatus be found guilty? The issue of culpability is a serious one, especially when exposure has been consensual. A study carried out by the Global Network of People Living with HIV/AIDS $(\mathrm{GNP}+)$ showed that for more than $90 \%$ of the convictions for HIV transmission, the route of transmission was consensual sexual intercourse (11). From a prevention perspective, is it appropriate or effective to place all the responsibility for preventing transmission on the infected? Might it create a false sense of security in the general population? Policy and legal research as well as population studies are needed on this issue.

\section{6. "New" Prevention Techniques: Male Circumci- sion}

In 2006, two trials testing the impact of male circumcision on HIV transmission were stopped due to efficacy rates of approximately $60 \%$, which made it unethical for the researchers to continue (12). While this news has been welcomed by governments, NGOs and the general population, it is unclear how best to address the "complex cultural, human rights, ethical and programmatic issue[s]" of making male circumcision a major HIV prevention method (13). It is evident that male circumcision does not provide complete protection and should only be expanded as a single component of a comprehensive prevention strategy if at all (14).

Important gender considerations also need to be examined. To date, the trials have only shown that male circumcision reduces female-to-male transmission. Is it possible that this intervention may undermine existing preventive strategies to reduce HIV infection? (15).

\section{COINFECTIONS}

\section{Coinfection with Hepatitis}

Hepatitis has become a global epidemic (16) and infection rates for hepatitis $\mathrm{C}$ have reached 5\% in some eastern European countries. The seventh research priority therefore addresses HIV coinfection with hepatitis $\mathrm{B}$ and $\mathrm{C}$ and how to raise awareness about it in the general public and among policymakers (17). Effective interventions for hepatitis B and C prevention are very similar to those for HIV prevention among IDUs, including needle and syringe exchange and information about safer injecting techniques in general. Research should also address hepatitis B vaccine coverage among adult populations.

\section{Discordant Couple Research}

From the natural course of IDU-driven epidemics in eastern Europe, it follows that for women, the infection risk comes from their sex partners, friends or husbands. In essence, the infection risk for women predominantly appears to be an issue of prevention in discordant couples, where the male partner is HIV-positive and the woman is HIV-negative. Conceptually, prevention interventions for women in our region still focus on youth, stigma, discrimination, migration, violence, rape, etc. rather than on "positive prevention" or partner management. Although the majority of women in these epidemics are infected by their HIV-positive partner, women's support groups do not address this primarily but address issues that are stereotypically perceived as "women” or gender problems. Research on discord- ant couples is very scarce and comes from different types of epidemics (e.g. mainly from Africa with a different heterosexual epidemic) (18).

This issue also relates to how "gender issues" are addressed in our region: these primarily young male-initiated epidemics have not led to a gender approach towards men, although such an approach is urgently needed since men have other typical health risks such as alcohol and violence related morbidity that may be better addressed using gender as entry point.

Another important issue for people living with HIV (PLHIV) has been reproduction - and not only natural reproduction, but medically assisted reproduction too, most notably through spermwashing. Since the risk of infecting the female partner or the child with washed sperm is minimal (19), this method has allowed some PLHIV to become fathers of seronegative children.

Other research areas related to the rights of infected people include the sexual health and well-being of PLHIV, contraception and safe abortion for PLHIV and the right to be vaccinated against the hepatitis B virus or the human papilloma virus (20).

\section{RIGHTS OF PEOPLE LIVING WITH HIV}

\section{Mother-to-child Transmission: Prevention and Counselling}

The prevention of mother-to-child transmission of HIV depends on the counselling of pregnant women and providing access to appropriate treatment. Little is known about the quality and availability of these services in many countries, but maternal health trends in some places are worrying. The number of abortions among HIV-positive women in some eastern European countries is much higher than in western Europe (21).

Research needs to look at who actually counsels these women - doctors, nurses, midwives or no one? Is the counselling objective, or is it dictated by the availability of treatment or other resources? And what precisely are pregnant women actually counselled on?

\section{Rapid Scale-up Issues}

Urgent operations research is needed to support the necessary scaling-up of best-practice and evidence-based interventions. Scaling-up - defined as "spreading social sector innovations into new geographic locations in order to achieve greater impact” (22) - is often restricted to implementing pilot projects re-inventing the wheel or pouring funds into new programmes. Although the need for rapid replication is obvious, innovative methods such as social franchising (23) are almost completely absent in the European region. On the other hand successful interventions such as the Back-up initiative (24) are often simply copied by other donors, who overlook the fact that the successes of such an intervention are not so easily replicated. Further, involving civil society and strengthening the health system is essential to the success of any rapid scale-up.

Another area for operations research is issues around quality of prevention: quality development, quality assurance in prevention, is extremely underdeveloped and under-researched. Do we measure what counts or do we count what is measurable? How do we know what works? Tools and instruments are lacking to assist successful implementation of interventions. 


\section{CONCLUSION}

While these ten areas in which to focus research energies before 2010 are not all-inclusive, all of them clearly need further research. Attending to these priorities will thus contribute to the achievement of universal access to HIV prevention, treatment, care and support in the European Region.

\section{REFERENCES}

1. UNDP. Reversing the epidemic: facts and policy options. Bratislava: United Nations Development Programme; 2004.

2. Jaffe HW, Valdiserri RO, De Cock KM. The reemerging HIV/AIDS epidemic in men who have sex with men. JAMA. 2007 Nov 28;298(20):241214.

3. Janssen RS, Holtgrave DR, Valdiserri RO, Shepherd M, Gayle HD, De Cock KM. The Serostatus Approach to Fighting the HIV Epidemic: prevention strategies for infected individuals. Am J Public Health. 2001 Jul;91(7):1019-24

4. Smith DM, Richman DD, Little SJ. HIV superinfection. J Infect Dis. 2005 Aug 1;192(3):438-44.

5. Baral S, Sifakis F, Cleghorn F, Beyrer C. Elevated risk for HIV infection among men who have sex with men in low- and middle-income countries 2000-2006: a systematic review. PLoS Med. 2007 Dec;4(12):e339.

6. Lines R, Stöver H. Silence still = death: 25 years of HIV/AIDS in prisons. In: Matic S, Lazarus JV, Donoghoe MC, editors. HIV/AIDS in Europe: moving from death sentence to chronic disease management. Copenhagen: WHO Regional Office for Europe; 2006. p. 67-85.

7. Lines R, Stöver H; United Nations Office on Drugs and Crime, World Health Organization, Joint United Nations Programme on HIV/AIDS. HIV/AIDS prevention, care, treatment and support in prison settings: a framework for an effective national response. New York: United Nations; 2006.

8. EuroHIV. HIV/AIDS Surveillance in Europe. End-year report 2006. No. 75. Saint-Maurice: French Institute for Public Health Surveillance; 2007.

9. Donoghoe MC, Lazarus JV, Matic S. HIV/AIDS in the transitional countries of Eastern Europe and Central Asia. Clin Med. 2005 SepOct;5(5):487-90.

10. WHO. WHO technical consultation in collaboration with the European AIDS Treatment Group and AIDS Action Europe on the criminalization of HIV and other sexually transmitted infections. Copenhagen: World Health Organization Regional Office for Europe; 2006.

11. Global Network of People Living with HIV/AIDS/Terrence Higgins Trust [homepage on the Internet]. Gaines H, Nyambe M. Criminalization of HIV transmission in Europe [cited 2007 Feb 20]. Available from: http://www. gnpplus.net/criminalisation/index.shtml.

12. Sawires SR, Dworkin SL, Fiamma A, Peacock D, Szekeres G, Coates TJ. Male circumcision and HIV/AIDS: challenges and opportunities. Lancet. 2007 Feb 24;369(9562):708-13.
13. Hankins, C. Male Circumcision. In: Seventh meeting UNAIDS Reference Group on HIV and Human Rights; 2007 Feb 12-14; Geneva. Geneva: Joint United Nations Programme on HIV/AIDS; 2007. p. 15.

14. Green LW, McAllister RG, Peterson KW, Travis JW. Male circumcision is not the HIV "vaccine" we have been waiting for! Future HIV Ther. 2008 May;2(3):193-9.

15. World Health Organization [homepage on the Internet]. Geneva: World Health Organization, the United Nations Population Fund, the United Nations Children's Fund, the World Bank, the UNAIDS Secretariat. Statement on Kenyan and Ugandan trial findings regarding male circumcision and HIV. 13 December 2006 [cited 2007 Feb 27]. Available from: http://www.who.int/mediacentre/news/statements/2006/s18/en/print. html.

16. World Hepatitis Awareness Day [homepage on the Internet]. WHAD [cited 2007 Feb 7]. Available from: http://www.worldhepatitisawarenessday. com/.

17. Lazarus JV, Shete PB, Eramova I, Merkinaite S, Matic S. HIV/hepatitis coinfection in Eastern Europe and new pan-European approaches to hepatitis prevention and management. Int J Drug Policy. 2007 Oct;18(5):42632.

18. Social Science Electronic Publishing [homepage on the Internet]. De Walque D. Discordant couples: HIV infection among couples in Burkina Faso, Cameroon, Ghana, Kenya, and Tanzania. World Bank Policy Research working paper. No. WPS3956 [cited 2008 Feb 1]. Available from: http://ssrn.com/abstract=923263.

19. Bujan L, Hollander L, Coudert M, Gilling-Smith C, Vucetich A, Guibert $\mathrm{J}$, et al; CREAThE network. Safety and efficacy of sperm washing in HIV-1-serodiscordant couples where the male is infected: results from the European CREAThE network. AIDS. 2007 Sep 12;21(14):1909-14.

20. Support for sexual and reproductive health in people living with HIV. In: Eramova I, Matic S, Munz M, editors. HIV/AIDS treatment and care: clinical protocols for the WHO European Region. Copenhagen: World Health Organization; 2007.

21. WHO. Europe survey on HIV/AIDS and antiretroviral therapy 2004 and 2006 [unpublished data]. Copenhagen: WHO Regional Office for Europe; 2006.

22. Dees JG, Battle Anderson B. Scaling for social impact: exploring strategies for spreading social innovations [document on the Internet]. Duke University: N.C. Center for Nonprofits, Pre-Conference workshop. 2003 Oct 8 [cited 2008 Feb 1]. Available from: http://www.fuqua.duke. edu/centers/case/documents/nc_center_master.ppt.

23. Association of German Foundations [homepage on the Internet]. The First International Social Franchise Summit; 2007 Dec 6; Berlin [cited 2008 Feb 4]. Available from: http://www.stiftungen.org/index. php?strg=3_560_657\&baseID=1651.

24. GTZ [homepage on the Internet]. Eschborn: BACKUP initiative: global financing mechanisms - opportunities and challenges [cited 2008 Feb 4]. Available from: http://www.gtz.de/en/themen/soziale-entwicklung/hivaids/4356.htm. 